\title{
Anti-Money Laundering Game between Banking Institutions and Employees in the Progressing CNY Internationalization
}

\author{
Dexiang Mei, Li Zhou \\ School of Economics and Management, Southwest Jiaotong University, Chengdu, China \\ Email: meidexiang1101@126.com
}

Received 22 March 2015; accepted 26 April 2015; published 30 April 2015

Copyright (C) 2015 by authors and Scientific Research Publishing Inc.

This work is licensed under the Creative Commons Attribution International License (CC BY). http://creativecommons.org/licenses/by/4.0/

(c) (i) Open Access

\begin{abstract}
Based on the establishment of imperfect dynamic game model of multiple node information sets, the paper analyzes the three equilibrium strategies of banking institutions (BIs) and employees (BEs) under Chinese government's different anti-money laundering (AML) efforts: both free of AML, BIs involved in AML but BEs away from AML, and both engaged in AML. It finds that Chinese government's AML effort will impact BIs' AML choice, and BIs' AML choice will affect BEs' AML choice. Only with the effective cooperation among the government, BIs, and BEs can we achieve the AML equilibrium strategy of the two gaming parties.
\end{abstract}

\section{Keywords}

CNY Internationalization, Banking Institutions (BIs), Banking Employees (BEs), Anti-Money Laundering (AML), Dynamic Game

\section{Introduction}

With China's growing economic strength and rising international status of RMB, CNY internationalization has become an inevitable trend. In September 29, 2013, China (Shanghai) Pilot Free Trade Zone was formally established, which effectively promotes the process of CNY internationalization. At the same time, China will face more tests and challenges on AML in the process of CNY internationalization. Therefore, AML legal regimes should be focused on to effectively combat the crime of money laundering and predicate offenses.

As a matter of fact, there are difficulties with implementation of AML regulations and one of the reasons is that BIs and BEs have some negative AML behaviors and even become money launderers. For example, On Ju- 
ly 17, 2012, A US Senate held a hearing on the HSBC' involving in money laundering, and pointed out that poor controls at the bank HSBC had failed to prevent effectively Mexican drug traffickers to launder billions of dollars in the United States in the past seven years. Then the New York state department of financial services (NYSDFS) revealed a money-laundering scandal that Standard Chartered bank through its New York branch jointed Iran's government to hide about 60,000 illegal transactions with more than $\$ 250$ billion for 9 years from 2001 to 2010. At the same time, "2010-China anti-money laundering report" pointed out that according to the ways of money laundering crime in our country, the bank account money laundering cases accounted for $66.3 \%$ of the total sample; according to money laundering crime involving industry in our country, banking industry money-laundering cases were the most and accounted for $75.4 \%$ of the total sample; according to the money laundering crime subject concentrated industry in our country, specific industry personnel or unit could engage in money laundering or help other criminals money laundering by taking advantage of their industry, and the cases involving in banking employees were most and accounted for $50 \%$.

In order to combat money laundering crime and maintain integrity of financial institutions and stability of the financial system in our country, we are faced with significant theoretical and practical issues that how our government, BIs and BEs work together to build an effective AML system in the process of CNY internationalization. Base on this, this paper will focus on behaviors among regulators, BIs and BEs by the method of game theory and seek AML equilibrium strategy of gaming parties. In this paper, section 2 is the literature review, and section 3 analyzes the behaviors among our government, BIs and Bes by building the game model. Conclusion shall be reached in the last section.

\section{Literature Review}

CNY internationalization relies on strong economic fundamentals, high international credit standing and advanced banking system [1]. In June 2010, led by the people's bank of China, the six ministries ${ }^{1}$ jointly issued "Notice on expanding the trials of settling cross-border trade accounts in RMB", which promotes effectively the internationalization of RMB. In this process, banking system shares financial profits from operating the offshore reserves of the currency, and undertakes traditional banking risk and non-traditional money laundering risk from home and abroad [3] [4].

In order to reduce money laundering activities and improve the efficiency of AML regimes, scholars from all over the world have made some researches on the reasons for failure of AML regulations, the building of AML system, AML methods, the legal system construction, efficiency evaluation and so on. As for the reasons for failure of AML regulations, Veiga et al. [5] find that according to the relationship between the AML regulations and outward foreign direct investment (OFDI), it has a negative correlation with the economic growth that BIs perform AML obligations, and AML regulations have an adverse effect on their country's economic. Idowu \& Abiol [6] find that even if banks take active part in the AML activities, the number of money laundering activities will not be decreased by analyzing the AML system from three banks of Nigeria through empirical model, and it is very difficult to be found by banks and regulators, thereby greatly reducing government revenues and worsening social environment. According to Araujo [7] BIs are rational economic man, and it is the rational choice that BIs aren't against money laundering due to the unreasonable mechanism by which AML takes a large number of fixed costs while the possibility of being investigated is very small without AML. In the same way, Araujo [8] argues, the reason why BEs are away from AML is inappropriate incentive mechanisms. In the opinion of Takagi et al. [9], financial institutions may make some decisions against AML law to maximize their own interests, thus damaging the interests of nation, society and citizens. Bajwa [10] says that although Pakistan's AML legal regimes are satisfactory, the implementation is partially inefficient, and one possible reason could be composition of the National Executive Committee and the General Committee itself.

From the perspective of the construction of AML system, Araujo [11] is the first to use evolutionary game theory to explain the relationship between BEs and BIs. He argues that the efficiency of AML system will be affected by some endogenous variables such as the AML mechanism-design, BIs' and Bes' AML willingness. At the same time, the article uses evolutionary game theory and proves that the number of banks willing to perform AML rules will affect the number of clerks engaged in AML. According to King [12], the risks of money laundering with general purpose reloadable prepaid cards issued outside of the United States are higher, and he

\footnotetext{
${ }^{1}$ Six ministries include: the people’s bank of China, ministry of finance, the ministry of commerce, general administration of customs, state administration of taxation and banking regulatory commission (CBRC) [2].
} 
examines both the regulatory response and the adoption of risk measures by the industry to minimize the attractiveness of GPR prepaid cards as a money laundering instrument. According to the major international experience in AML supervision on private banking, Wenjun Tong [13] gives suggestions for strengthening the regulatory measures of AML for private banking in China. Muhammad [14] finds that employee training has an effect on money laundering in banking system. He suggests that special budget should be allocated for the capacity building of employees through training and implementation of AML regulations should be timely, transparent and consistent. Yeoh [15] argues that early exposing wrongdoings may decrease severity of consequences, and revamping of the suspicious activity reports procedures required under AML laws is helpful to reduce defensive reporting and enable enforcement agencies to have more effective focus on remedial actions.

Speaking of AML methods, Takats [16] analyzes the relationship between banks and financial regulators by using a game model. He thinks that banks should be compensated for the costs of submitting suspicious reports, and penalties should be decreased for submitting a few suspicious reports. Meanwhile he uses the principal-agent model to explain the beneficial relationships between government and banks. Shenggang Yang et al. [17] make use of principal-agent model to discuss the game relation between commercial banks and regulatory authority. And at the presupposition that the restrictive mechanism had existed in AML, they design an incentive mechanism that can help commercial banks act in conformity with regulatory authority's goals.

According to Hexin Hou [18], with the increasing number of money laundering crime, the AML legislation has become one of the urgent events of legal framework construction in China, and law suitability and legal basis of AML work have become more important and pressing than ever. Yingjie Wang [19] discusses the AML legislative system and institutional framework of the European countries and America etc. Further based on this, he analyzes the existing problems of China's AML system now by comparing with that of European countries and America. With the growing threat of global money laundering, Rahman [20] argues that it will be necessary to examine the banking secrecy rule in the AML and other relevant statutes in detail.

Xu Tang et al. [21] analyze and quantify the effectiveness of AML system in China by using questionnaires given to the financial sector, and states that in general, China's AML system is largely effective, but flawed in AML legislation. In addition, in the Indian, it is difficult to establish the effectiveness of enforcement function of AML. In fact, it is judged on the basis of convictions and confiscations due to the limited availability of data [22]. In order to reduce the monitoring costs of AML and increase the effect of AML, Shaobing Peng et al. [23] build an evaluating system for the efficiency of AML internal control, which can be used for external supervision and internal management.

In conclusion, although the domestic and foreign scholars have done a lot of research on AML, the studies on the AML game relationship among BIs, BEs and regulators is almost blank in the context of the CNY internationalization. Based on the CNY internationalization, this paper analyses the AML equilibrium strategies of BIs and BEs under Chinese government's different AML efforts. The topic has important theoretical and realistic significance.

\section{Dynamic Game Research on AML Strategy of BIs and BEs}

\subsection{Assumptions}

To facilitate the modeling and analysis, firstly we make the following assumptions:

Assumption 1: BIs' and BEs' strategy space is the same: engaged in AML, free of AML.

Assumption 2: One BI only hires one BE.

Assumption 3: The strategy goal of BIs and BEs is to maximize their revenues.

Assumption 4: Whether BEs are involved in AML or not, BIs will pay them the same wages.

Assumption 5: The two gaming parties namely BIs and BEs have a clear knowledge of the strategy space and the profit function of his opponents in the game. They are both initiative and rational when choosing strategies.

Assumption 6: When RMB is fully internationalized, the profit of BIs engaged in RMB internationalization business is $D$. The degree of RMB internationalization is $h, 0 \leq h \leq 1$ and the profit of BIs engaged in RMB internationalization business in the process of RMB internationalization is $h D$.

\subsection{The Profits of the Two Gaming Parties under the Different Strategy Space}

(1) Based on the above assumptions, firstly we analyze the profit of BIs under different strategies. 
For BIs, when Chinese government's AML effort is small and BEs and BIs are both involved in AML, the profit of BIs is as follows:

$$
\Pi_{11}^{a}=(1-t) f_{a}^{-}-w_{a}^{-}+h D
$$

where: $\Pi_{11}^{a}$ is the profit of BIs when BEs and BIs are both involved in AML.

$f_{a}^{-}$is the output of a BI involved in AML and hiring a BE involved in AML.

$t f_{a}^{-}, 0 \leq t \leq 1$ is the costs for a BI which meets its AML obligations when a BE is engaged in AML, known as the bank's compliance costs. BI will be not punished by regulators because of its AML.

$w_{a}^{-}$is the wage of a BE involved in AML and hired by a BI involved in AML.

$h D$ is the profit of BIs engaged in RMB internationalization business in the process of RMB internationalization.

When Chinese government's AML effort is small and BEs are away from AML but BIs are involved in AML, the profit of BIs is as follows:

$$
\Pi_{12}^{a}=(1-t) \underline{f}_{a}-\underline{w}_{a}+h D
$$

where: $f_{a}$ is the output of a BI engaged in AML and hiring a BE away from AML.

$t \underline{f}_{a}$ is the costs for a BI which meets its AML obligations when a BE is free of AML, known as the bank's compliance costs. BI will be not punished by regulators because of its AML.

$\underline{w}_{a}$ is the wage of a BE away from AML and hired by a BI involved in AML.

When Chinese government's AML effort is small and BEs are involved in AML but BIs are away from AML, the profit of BIs is as follows:

$$
\Pi_{11}^{i}=f_{i}-w_{i}+h D
$$

where: $f_{i}$ is the output of a BI away from AML and hiring a BE involved in AML.

$w_{i}$ is the wage of a BE involved in AML and hired by a BI away from AML.

When Chinese government's AML effort is small and BEs and BIs are both away from AML, the profit of BIs is as follows:

$$
\Pi_{12}^{i}=f_{i}-w_{i}+h D
$$

When Chinese government's AML effort is big and BEs and BIs are both involved in AML, the profit of BIs is as follows:

$$
\Pi_{11}^{a}=(1-t) f_{a}^{-}-w_{a}^{-}+h D
$$

When Chinese government's AML effort is big and BEs are away from AML but BIs are involved in AML, the profit of BIs is as follows:

$$
\Pi_{12}^{a}=(1-t) \underline{f}_{a}-\underline{w}_{a}+h D
$$

When Chinese government's AML effort is big and BEs are involved in AML but BIs are away from AML, the profit of BIs is as follows:

$$
\Pi_{11}^{i i}=f_{i}-w_{i}-p k
$$

where: $p$ is Chinese government's penalties for BIs away from AML.

$k$ is the amount of money laundering supported by BIs.

When Chinese government's AML effort is big and BEs and BIs are both away from AML, the profit of BIs is as follows:

$$
\Pi_{12}^{i i}=f_{i}-w_{i}-p k
$$

The above, Equation (1) is equal to Equation (5), Equation (2) is equal to Equation (6), Equation (3) is equal to Equation (4), Equation (7) is equal to Equation (8), and $\underline{w}_{a}$ is equal to $w_{i}$. 
(2) Based on the above assumptions, further we analyze the profit of BEs under different strategies.

For BEs, when Chinese government's AML effort is small and BEs and BIs are both involved in AML, the profit of BEs is as follows:

$$
\Pi_{21}^{a}=\vec{w}_{a}-c
$$

where: $\Pi_{21}^{a}$ is the profit of BEs when BIs and BEs are both involved in AML.

$C$ is the cost of acquiring AML knowledge for BEs.

When Chinese government's AML effort is small and BEs are away from AML but BIs are involved in AML, the profit of BEs is as follows:

$$
\Pi_{21}^{i}=w_{i}
$$

When Chinese government's AML effort is small and BEs are involved in AML but BIs are away from AML, the profit of BEs is as follows:

$$
\Pi_{22}^{a}=w_{i}-c
$$

When Chinese government's AML effort is small and BEs and BIs are both away from AML, the profit of BEs is as follows:

$$
\Pi_{22}^{i}=w_{i}
$$

Whether Chinese government's AML effort is small or big, the profit of BEs will be not affected. That means when the Chinese government's AML effort is big, the profit of BEs is the same as the above.

\subsection{Game Model and Analysis}

For BEs, the choice of their strategy depends on BIs'. If BIs choose AML, the rational BEs may choose AML or not. If BIs choose to be free of AML, BEs will make the same choice. Therefore, a rational BE should observe or speculate BI's strategy before choosing his strategy.

For BIs, the choice of their strategy is influenced by BEs' strategy and the punishment risk of their being away from AML. And the impact of the latter is larger than the former. Because the choice of BIs' strategy faces the uncertain punishment risk without AML, we create a game party Chinese government which decides the punishment risk. Suppose the game party Chinese government's strategy space is: its AML effort is small, or its AML effort is big. Thus we convert uncertainty of the punishment risk into the dummy game party's choice. In this vein, BIs and BEs can't be entirely sure of the Chinese government's choice, but they can estimate the probability distribution based on the relevant information. So it is a dynamic game of complete but imperfect information. Because Chinese government is a dummy game party, its profit will not be considered. Through such a process, we can transform the two-person game into three-side dynamic game of imperfect information, and the extensive form game may be given as shown in Figure 1.

Now, we use the backward induction to analyze the game.

Firstly, we will analyze the optimal strategy of the BEs in the second stage. From Figure 1, when BIs are away from AML, because $\Pi_{22}^{a}=w_{i}-c<\Pi_{22}^{i}=w_{i}$ is supported forever, the optimal strategy of BEs is away from AML. According to this, we remove bad strategy combination of A and B. BIs' away from AML results in BEs' away from AML, and thus the illegal behavior of money laundering can't be cracked down on. In the case that BIs choose AML, if the wage of BEs involved in AML and paid by BIs involved in AML is higher, that is to say, $\Pi_{21}^{a}=\vec{w}_{a}-c>\Pi_{21}^{i}=w_{i}$ is supported, being engaged in AML is BEs' optimal strategy. On the contrary, when BIs involved in AML pay lower wage of BEs involved in AML-in other words, $\Pi_{21}^{a}=\vec{w}_{a}-c<\Pi_{21}^{i}=w_{i}$ is supported, being away from AML is BEs’ optimal strategy.

Secondly, we will discuss the optimal strategy of the BIs in the first stage. The choice of BIs' strategy depends on the punishment risk of their being away from AML. Assume that the probability of Chinese government choosing big AML effort is $\pi$, and BIs' attitude towards risk is neutral. In this case, BIs’ optimal strategy should satisfy as follows:

$$
\max \left\{\left(\pi \times \Pi_{12}^{i i}+(1-\pi) \times \Pi_{12}^{i}\right), \Pi_{11}^{a}, \Pi_{12}^{a}\right\}, \quad 0 \leq \pi \leq 1
$$




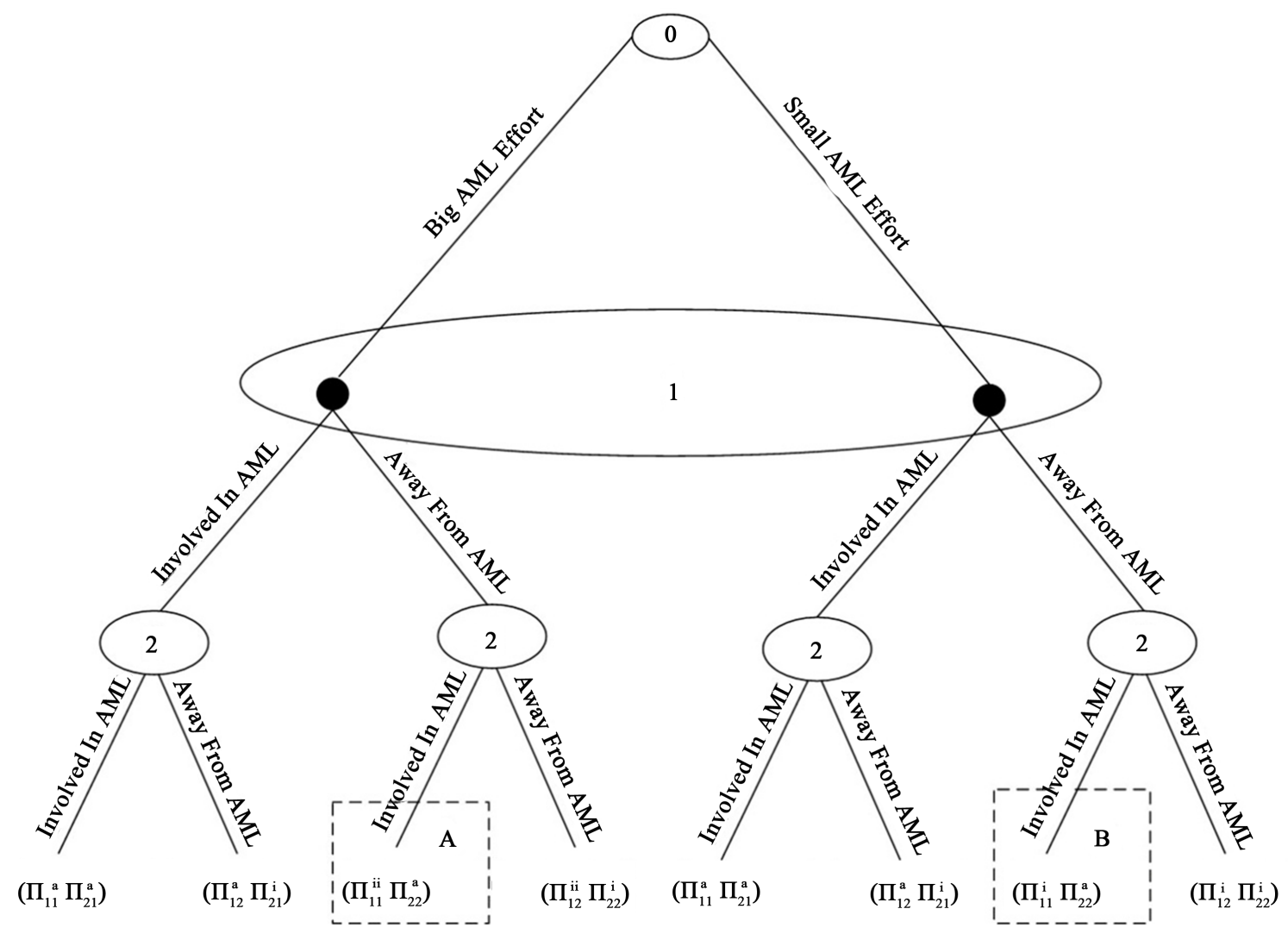

Figure 1. Two-person dynamic Game of BIs and BEs in extensive form.

Therefore, when $\left(\pi \times \Pi_{12}^{i i}+(1-\pi) \times \Pi_{12}^{i}\right)<\Pi_{12}^{a}$ or $\left(\pi \times \Pi_{12}^{i i}+(1-\pi) \times \Pi_{12}^{i}\right)<\Pi_{12}^{a}$ is supported, being engaged in AML is BIs' optimal strategy. When $\left(\pi \times \Pi_{12}^{i i}+(1-\pi) \times \Pi_{12}^{i}\right)>\max \left\{\Pi_{11}^{a}, \Pi_{12}^{a}\right\}$ is supported, being away from AML is BIs' optimal strategy.

There are three possibilities about the result of the game. Because $\Pi_{22}^{a}=w_{i}-c<\Pi_{22}^{i}=w_{i}$ is supported forever, When $\left(\pi \times \Pi_{12}^{i i}+(1-\pi) \times \Pi_{12}^{i}\right)>\max \left\{\Pi_{11}^{a}, \Pi_{12}^{a}\right\}$ is supported, being free of AML is the optimal strategy of BIs and BEs, that is to say, BIs and BEs reach the non-anti-money laundering equilibrium; When $\Pi_{11}^{a}>\max \left\{\left(\pi \times \Pi_{12}^{i i}+(1-\pi) \times \Pi_{12}^{i}\right), \Pi_{12}^{a}\right\}$ and $\Pi_{21}^{a}=\vec{w}_{a}-c>\Pi_{21}^{i}=w_{i}$ are both supported, being engaged in AML is optimal strategy of BIs and BEs-in other words, BIs and BEs reach the AML equilibrium; When $\Pi_{12}^{a}>\max \left\{\left(\pi \times \Pi_{12}^{i i}+(1-\pi) \times \Pi_{12}^{i}\right), \Pi_{11}^{a}\right\}$ and $\Pi_{21}^{a}=\vec{w}_{a}-c<\Pi_{21}^{i}=w_{i}$ are both supported, being engaged in AML is BIs' optimal strategy while being free of AML is BEs' optimal strategy. That means that BIs and BEs reach the equilibrium of AML and non-anti-money laundering.

\section{Conclusion}

When Chinese government's AML effort is small, being both free of AML is the game equilibrium of BIs and BEs, and the illegal behavior of money laundering cannot be cracked down on. When Chinese government's AML effort is big, BIs will be engaged in AML and BEs will be away from AML, thus declining the effectiveness of combating illegal money laundering activities. When Chinese government's AML effort is big, being engaged in AML is BIs' and BEs' optimal strategy, and the action of cracking down on illegal money laundering is effective. Chinese government's AML effort will impact BIs' AML choice, and BIs' AML choice will affect BEs' AML choice. Only if the government, BIs and BEs cooperate can we achieve the AML equilibrium strategy of the two gaming parties. 


\section{Sponsored}

This research is sponsored by the National Social Science Foundation of China (NO. 12XJY028) and the Humanities and Social Sciences Foundation of the Ministry of Education, People's Republic of China (NO. 11YJA790033).

\section{References}

[1] Zhao, H.K. (2003) RMB Is Capable of Becoming One of the World Currencies. Economic Research Journal, 3, 54-91. http://en.cnki.com.cn/article_en/cjfdtotal-jjyj200303006.htm

[2] Anti Money Laundering Bureau of the People’s Bank of China (2011) 2010-China Anti-Money Laundering Report. Chinese Financial Publishing House, Beijing.

[3] Chen, Y.L., Wang, F. and Yang, M. (2005) Currency Internationalization as a National Competitive Strategy: US Dollar's Empirical Evidence. Economic Research Journal, 2, 35-44. http://www.en.cnki.com.cn/article_en/cjfdtotal-jijyj200502003.htm

[4] Ba, S.S. (2004) Evaluation of the Risks Faced by Hongkong Banking in the Operation of RMB Business. Management World, 5, 33-38. http://en.cnki.com.cn/article_en/cjfdtotal-glsj200405004.htm

[5] Veiga, L., Andrade, J. and Rossi, A. (2006) Money Laundering, Corruption and Growth: An Empirical Rationale for a Global Convergence on Anti-money Laundering Regulation. Proceedings of the 34th Brazilian Economics Meeting.

[6] Idowu, A. (2012) Anti-Money Laundering Policy and Its Effects on Bank Performance in Nigeria. Business Intelligence Journal, 6, 367-373.

[7] Araujo, R. (2008) Assessing the Efficiency of the Anti-Money Laundering Regulation: An Incentive-Based Approach. Journal of Money Laundering Control, 11, 67-75. http://search.proquest.com/docview/235884174/90657AAB58E845E2PQ/1?accountid=42340 http://dx.doi.org/10.1108/13685200810844505

[8] Araujo, R. (2009) Are Labor Contract Efficient to Combat Crime? Journal of Financial Crime, 16, 255-261. http://dx.doi.org/10.1108/13590790910973098

[9] Takagi, S. and Shi, Z.Y. (2011) Exchange Rate Movements and Foreign Direct Investment (FDI): Japanese Investment in Asia, 1987-2008. Japan and the World Economy, 23, 265-272. http://econpapers.repec.org/article/eeejapwor/v 3a23 3ay 3a2011 3ai 3a4 3ap 3a265-272.htm http://dx.doi.org/10.1016/j.japwor.2011.08.001

[10] Bajwa, S.S. (2013) A Comparative Analysis of Anti-Money Laundering Law in the United Kingdom and Pakistan. SSRN Working Paper Series.

[11] Araujo, R.A. (2010) An Evolutionary Game Theory Approach to Combat Money Laundering. Journal of Money Laundering Control, 13, 70-78. http://dx.doi.org/10.1108/13685201011010236 http://search.proquest.com/docview/235888484/3CFF86C9F8794F26PQ/1?accountid=42340

[12] King, D. (2013) Have Anti-Money Laundering Measures Kept Pace with the Rapid Growth of GPR Prepaid Cards? Retail Payments Risk Forum Working Paper, 2, 1-15. http://citeseerx.ist.psu.edu/viewdoc/summary;jsessionid=36E58814E53BB2CB24617A3EF8A09021?doi=10.1.1.303.2 $\underline{392}$

[13] Tong, W.J. (2014) Money-Laundering Risk and Regulatory Measures on Anti-Money Laundering of Private Banking. Journal of Financial Development Research, 5, 45-48. http://en.cnki.com.cn/article_en/cjfdtotal-sdjr201405009.htm

[14] Kemal, M.U. (2014) Anti-Money Laundering Regulations and Its Effectiveness. Journal of Money Laundering Control, 17, 416-427. http://dx.doi.org/10.1108/JMLC-06-2013-0022 http://search.proquest.com/docview/1660771476/973DE5AC392A4688PQ/1 ?accountid=42340

[15] Yeoh, P. (2014) Enhancing Effectiveness of Anti-Money Laundering Laws through Whistle Blowing. Journal of Money Laundering Control, 17, 327-342. http://dx.doi.org/10.1108/JMLC-06-2013-0020 http://search.proquest.com/docview/1660771070/89498A8802E341C2PQ/1 ?accountid=42340

[16] Takáts, E. (2011) A Theory of “Crying Wolf”: The Economics of Money Laundering Enforcement. Journal of Law, Economics and Organization, 27, 32-78. http://dx.doi.org/10.1093/jleo/ewp018 http://search.proquest.com/docview/854434948/4DBD9110B9FC4F5FPQ/1 ?accountid=42340

[17] Yang, S.G., He, J. and Zeng, Y. (2007) Anti-Money Laundering Game between Regulatory Authority and Commercial Bank and the Principal-Agent Problem. Journal of Financial Research, 1, 71-83.

[18] Hou, H.X. (2006) On the Anti-Money Laundering Law. Journal of Financial Research, 8, 173-179. http://en.cnki.com.cn/article_en/cjfdtotal-jryj200608016.htm 
[19] Wang, Y.J. (2005) Establish Anti-Money Laundering Mechanism of Conforming to Our Country Financial Situation as Soon as Possible. Journal of Financial Research, 5, 146-152.

[20] Rahman, A.A. (2014) Combating Money Laundering and the Future of Banking Secrecy Laws in Malaysia. Journal of Money Laundering Control, 17, 219-229. http://dx.doi.org/10.1108/JMLC-09-2013-0036 http://search.proquest.com/docview/1536448919/2755228F166B4B0CPQ/1 ?accountid=42340

[21] Tang, X., Shi, Y.Y. and Cao, Z.Y. (2009) On the Effectiveness of the China's Anti-Money Laundering Work. Journal of Financial Research, 8, 1-16. http://en.cnki.com.cn/article_en/cjfdtotal-jryj200908004.htm

[22] Viritha, B., Mariappan, V. and Haq, I.U. (2015) Suspicious Transaction Reporting: An Indian Experience. Journal of Money Laundering Control, 18, 2-16. http://dx.doi.org/10.1108/JMLC-11-2013-0046 http://search.proquest.com/docview/1642190122/4BDE415701AD4EE3PQ/1?accountid=42340

[23] Peng, S.B. (2013) On Evaluation Index of Efficiency of Banking Anti-Money Laundering Internal Control. Studies of International Finance, 1, 66-76. 